\title{
A case of persistent portal hypertension following ligation of a large porto-systemic shunt during cadaveric donor liver transplantation
}

Nishanthan Shanthanayagam ${ }^{1}$, Bhagya M Gunetilleke ${ }^{1}$, Aruna P Weerasuriya ${ }^{1}$, Madunil A Niriella ${ }^{2}$, Anuradha S Dassanayake ${ }^{3}$, Ruwan Dissanayake ${ }^{4}$, Rohan C Siriwardana ${ }^{1}$

Ceylon Medical Journal 2020; 65: 32-33

DOI: http://doi.org/10.4038/cmj.v65i1-2.9135

\section{Introduction}

A 48-year-old cirrhotic patient worked up for liver transplant had large porto systemic shunt connecting left portal vein to external iliac vein (Figure 1).

He underwent cadaveric donor liver transplantation. Liver weighed $1200 \mathrm{~g}$. During surgery shunt was ligated (Figure 2).

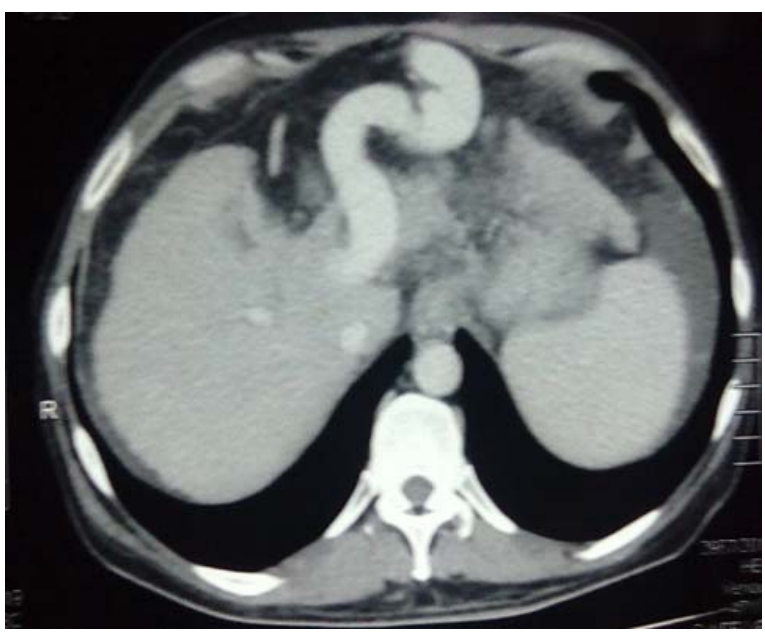

Figure 1. Recanalized para umbilical vein-axial images from portovenous phase CT.

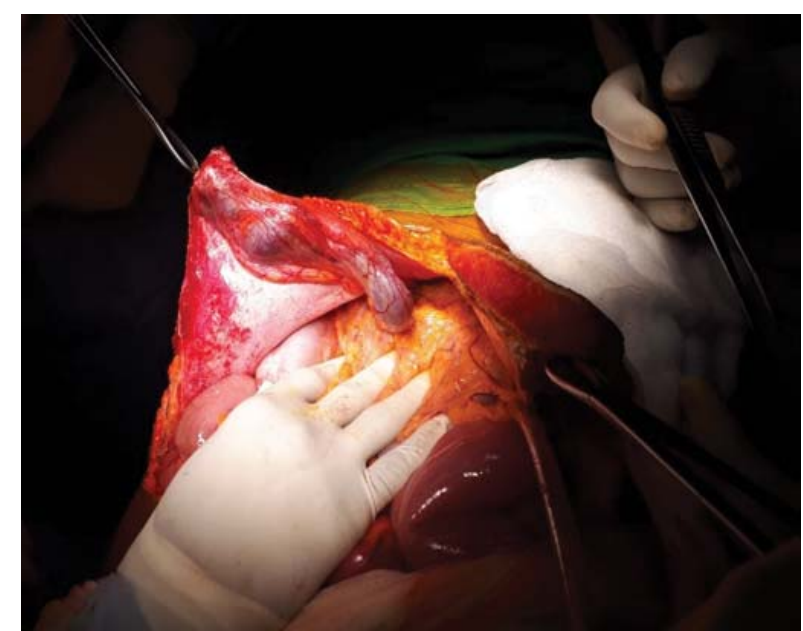

Figure 2. Intra operative image of large recanalized para umbilical vein in falciform ligament.

After ligation, small bowel gradually became congested. Donor liver was implanted using side-to-side piggyback technique. The congestion was persistent. There was no venous outflow obstruction. Portal venous pressure was 19 $\mathrm{mm} / \mathrm{Hg}$.

During the post-operative period, patient's lactate and liver biochemistry was gradually rising and succumbed on the forth post-operative day due to primary non function. The donor liver biopsy did not show any preservation injury or fatty liver disease.

${ }^{1}$ Department of Surgery, Faculty of Medicine, Ragama, ${ }^{2}$ Department of Medicine, Faculty of Medicine, Ragama, ${ }^{3}$ Department of Pharmacology, Faculty of Medicine, Ragama, ${ }^{4}$ Liver Transplantation Unit, National Hospital of Sri Lanka.

Correspondence: RCS, e-mail: <rohansiriwardana@yahoo.com>. Received 17 December 2019 and revised version 05 March 2020 accepted 02 July 2020. 
Sappy described many porto systemic shunts where accessory veins entering liver capsule enlarging to become the only site of shunting. One of the sites is inferior vein of Sappey left portal vein, inferior epigastric vein joining to external iliac vein [1].

Having a portal pressure over $15 \mathrm{~mm} / \mathrm{Hg}$ leads to poor graft survival [2] classically described in partial grafts. A similar case associated with outsized shunt in the setting of full size graft was not reported previously. A temporary porto-caval shunt to manipulate the portal pressure could have led to a favourable outcome in this patient [3].

In conclusion, ligation of large porto-systemic shunts can lead to alteration of post-transplant haemodynamics.

Porto systemic shunts are common in cirrhotics. Abnormally large shunts can lead to alterations in portal flow dynamics. This case describes a rare fatal outcome during liver transplantation after ligation of unusually large vein of Sappy.

\section{Consent}

The first degree relatives of the diseased has given written consent for the case to be published.

\section{References}

1. Ibukuro K, Fukuda H, Tobe K, Akita K, Takeguchi T. The vascular anatomy of the ligaments of the liver: Gross anatomy, imaging and clinical applications. $\mathrm{Br} J$ Radiol. 2016; 89: 20150925.

2. Ogura Y, Hori T, El Moghazy WM, et al. Portal pressure $<15 \mathrm{~mm} \mathrm{Hg}$ is a key for successful adult living donor liver transplantation utilizing smaller grafts than before. Liver Transpl. 2010; 16: 718-28.

3. Kinaci E, Kayaalp C. Portosystemic Shunts for "Too Smallfor-Size Syndrome” After Liver Transplantation: A Systematic Review. World J Surg. 2016; 40: 1932-40. 